\title{
SEGREGAÇÃO E SILENCIAMENTOS NA EXPERIÊNCIA DE MULHERES EM REGIÕES PERIFÉRICAS
}

\author{
Marcelo Bordin \\ Geógrafo, Cientista Político e Doutorando em Sociologia \\ Centro de Estudos em Segurança Pública e Direitos Humanos - UFPR \\ marcelobordin05@gmail.com \\ Maria Izabel Machado \\ Universidade Federal de Goiás \\ Doutora em Sociologia \\ mariaizabelmachado@ufg.br
}

\begin{abstract}
RESUMO
O artigo tem por finalidade analisar experiências de mulheres em um bairro do município de Almirante Tamandaré, participantes de um clube de trocas, prática ligada à economia solidária. O cotidiano das participantes se dá em meio a um contexto de segregação socioespacial e ao acúmulo de desvantagens tais como a pobreza e as assimetrias de gênero. A pergunta de análise, portanto, centra-se no modo como essas mulheres vivenciam a segregação em suas múltiplas expressões. A metodologia para coleta de dados incluiu observação participante e entrevistas individuais e coletivas. Dentre achados de pesquisa, está o desenvolvimento de estratégias de sobrevivência individuais e coletivas e a construção de redes de proteção próxima, a partir dos padrões de sociabilidade e das contingências impostas pelo meio.
\end{abstract}

Palavras-chaves: Clube de trocas. Segregação Sócio Espacial. Solidariedade.

\section{ABSTRACT}

The purpose of this article is to analyze the experiences of women in a neighborhood in the municipality of Almirante Tamandaré, participants of an exchange club, a practice linked to solidarity economy. Participants' daily life occurs in the context of socio-spatial segregation and the accumulation of disadvantages such as poverty and gender asymmetries. The question of analysis, therefore, focuses on how these women experience segregation in their multiple expressions. The methodology for data collection included participant observation and individual and collective interviews. Among research findings is the development of individual and collective survival strategies and the construction of close protection networks, based on sociability standards and the contingencies imposed by the environment.

Key-words: Exchanges Club. Socio-Spatial Segregation. Solidarity.

\section{RESUMEN}

El artículo tiene por finalidad analizar experiencias de mujeres en un barrio del municipio de Almirante Tamandaré, participantes de un club de intercambios, práctica conectada a la economía solidaria. El cotidiano de las participantes se da en medio de un contexto de segregación socio espacial y la acumulación de desventajas tales como la pobreza y las asimetrías de género. La pregunta de análisis, por lo tanto, se centra en el modo en que estas mujeres experimentan la segregación en sus múltiples expresiones. La metodología para recolección de datos incluyó observación participante y entrevistas individuales y colectivas. Entre los hallazgos de investigación está el desarrollo de estrategias de supervivencia individuales y colectivas y la construcción de redes de protección cercana, a partir de los patrones de sociabilidad y de las contingencias impuestas por el medio.

Palabras clave: Club de Intercambios. Segregación Socioespacial. Solidaridad. 


\section{INTRODUÇÃO}

O presente artigo tem como proposta analisar a experiência de mulheres participantes de um clube de trocas, prática ligada à economia solidária, no tocante as múltiplas segregações e contingenciamentos dados a partir do território, das condições de pobreza e das assimetrias de gênero.

A sobreposição de desvantagens acumuladas produz sobre as mulheres sociabilidades regidas pelo medo do marido, da violência fora de casa, de não conseguir ordenar o vivido de modo a construir uma narrativa coerente de si. Em regiões marcadas pela atuação do tráfico e onde os equipamentos públicos se restringem à ação policial, que acentua a criminalização da pobreza, resta às mulheres estabelecerem estratégias de proteção individuais e coletivas.

Saber falar, saber quando e o que falar como estratégias de sociabilidade podem demarcar a fronteira entre arriscar a vida ou emancipar-se. A análise que segue, portanto, centra-se nesse saber fruto da experiência de algumas mulheres participantes de um clube de trocas na região metropolitana de Curitiba. Os enunciados desses sujeitos imbricam trajetórias pessoais, conjunturas e elementos estruturais que possibilitam sua apreensão por meio da noção de experiência como narrada pelos sujeitos que as vivenciam.

Partir dos sujeitos permite ir além de leituras dicotomizantes de romantização da pobreza ou de demonização das forças de segurança pública. Trata-se de apreender as lógicas internas produzidas nos processos de interação e, por meio dos significados assumidos e/ou recriados, compor uma espécie de "paisagem do medo", na qual se articulam uma sociabilidade dos confinados (SILVA, 2008) e também redes de proteção próxima (MACHADO, 2012).

A coleta de dados se deu segundo metodologias qualitativas que incluíram observação participante durante os encontros no clube de troca, entrevista coletiva e entrevistas em profundidade realizadas com oito mulheres. Os nomes foram alterados para preservar as entrevistadas.

Para responder à pergunta sobre o modo como as mulheres estão experimentando a segregação, conduziremos a reflexão da seguinte forma: na primeira seção apresentamos os dados empíricos sobre a região e o perfil dos sujeitos da pesquisa. A seção seguinte é dedicada às leituras acerca dos múltiplos silenciamentos a que estão submetidas essas mulheres. Na terceira e última seção analisamos o silêncio e o falar como estratégias possibilitadoras do existir.

\section{Território, o clube de trocas e as mulheres}

O território em que está situado o clube de trocas estudado se encontra no município de Almirante Tamandaré, cidade da região metropolitana de Curitiba. O município possui uma população, estimada em 2017, de 115.365 habitantes, segundo o IBGE ${ }^{1}$, com um IDHM de 0,699 para o ano de $2010^{2}$. Ainda que possa parecer um bom indicador, o referido município enfrenta inúmeros problemas, sendo considerado dormitório para inúmeras pessoas que trabalham na capital do estado, somado ao fato de que $55 \%$ de sua população reside atualmente na área rural (IPARDES, 2016). O município assistiu uma série de atos de violência letal contra as mulheres entre os anos de 1994 e 2002 e que continuam sem solução, ainda que mais de 20 suspeitos tivessem sido detidos, inclusive alguns policiais ${ }^{3}$. Além desses casos de maior visibilidade durante a coleta de dados, o assassinato de mulheres se mantinha como dos medos constantes como relatados em entrevista.

\footnotetext{
${ }^{1}$ Disponível em

http://ftp.ibge.gov.br/Estimativas_de_Populacao/Estimativas_2017/estimativa_TCU_2017.pdf - acesso em 10 mar 2017.

${ }^{2}$ Disponível em

https://cidades.ibge.gov.br/xtras/temas.php?lang=\&codmun=410040\&idtema=118\&search=parana|almiran te-tamandare|\%C3\%8Dndice-de-desenvolvimento-humano-municipal-idhm acesso em 11 mar 2017.

${ }^{3}$ Disponível em http://www.gazetadopovo.com.br/vida-e-cidadania/morte-de-dezenas-de-mulheresaguarda-solucao-em-tamandare-amumieg62lo9bg6382ygb5u8e - acesso em 20 jun 17.
} 
Entre os desafios para a superação desse cenário está a dificuldade de acesso a informações que possibilitem medidas efetivas por parte dos agentes envolvidos. Apenas a partir 2012, por exemplo, foi possível obter dados da Secretaria de Segurança Pública discriminados por município. De 2007 até 2011 as estatísticas eram divulgadas por Áreas Integradas de Segurança Pública, denominação que agrupava diversos municípios e que visava a melhorar a coordenação entre as forças policiais civis e militares.

FIGURA 1 - Quantidade de homicídios dolosos em Almirante Tamandaré, de 2012 até o primeiro semestre de 2017.

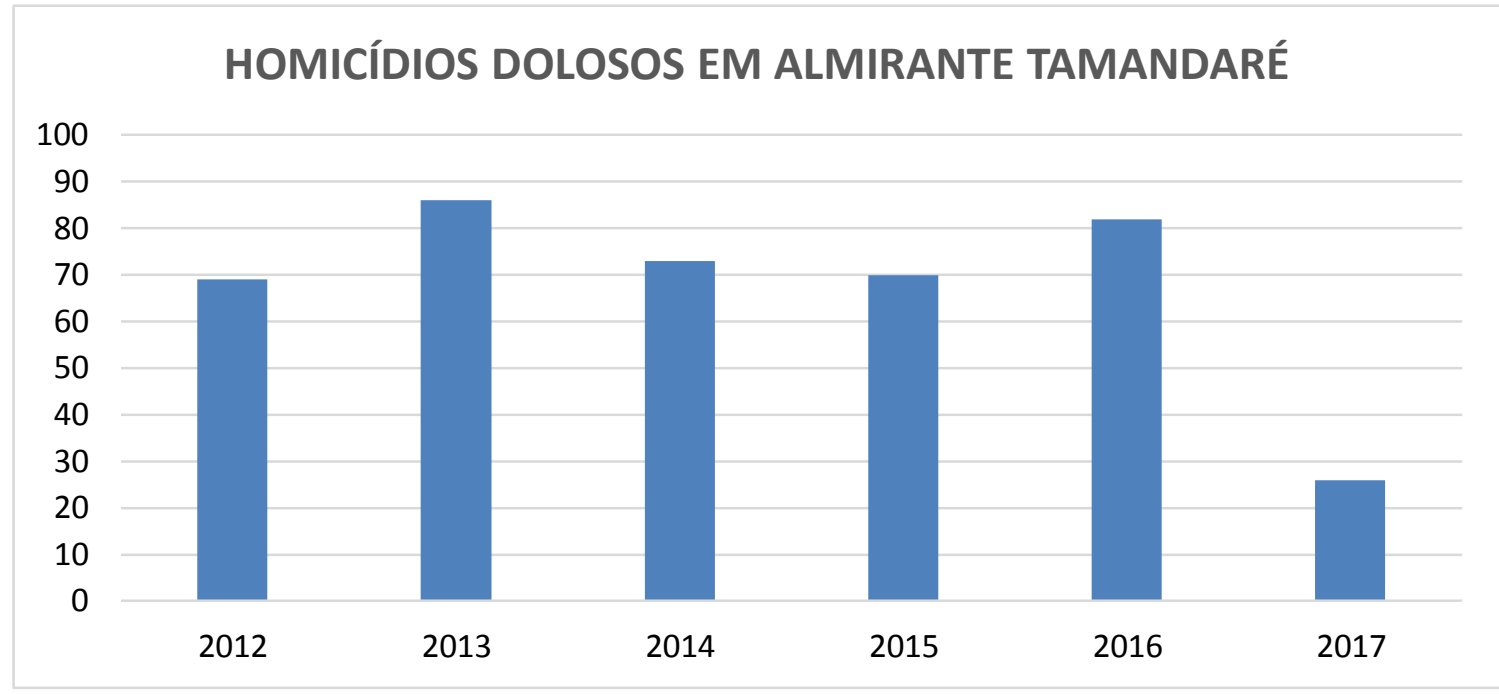

Fonte - CAPE/SESP Pr. Disponíve

http://www.seguranca.pr.gov.br/modules/conteudo/conteudo.php?conteudo=38 - Organizado pelos autores.

Administrar a vida cotidiana nesse contexto exige das populações periféricas, em especial das mulheres a quem toca comumente o cuidado com os filhos e demais membros da família, estratégias capazes de fazer frente a indicadores altos de violência letal. Isso para não citarmos os demais tipos de crimes, impondo formas de gerir a vida que assegurem minimamente a sobrevivência à despeito da ausência de equipamentos públicos e dos padrões de sociabilidade ligados à violência. Dentre as diversas estratégias possíveis estão a associações de diversos tipos que, em geral, demandam baixo investimento de recursos materiais e se adéquam às condições de participação de seu público alvo. No caso aqui analisado, trata-se de um clube de trocas que poderia ser definido de maneira simples como uma associação informal autogerida. Ligados à economia solidária, os clubes contam com uma forma horizontal de organização, além da participação equitativa nos resultados e a ênfase na condução democrática dos processos decisórios, características comuns aos empreendimentos econômico solidários. Têm como principal objetivo reunir pessoas para troca de produtos e serviços sem a intermediação do dinheiro.

Inspirado em uma iniciativa similar na Argentina, o primeiro clube de trocas foi criado no Brasil em 2001 com o intuito de eliminar as filas de assistência social de algumas paróquias em bairros periféricos de Curitiba. Os clubes viriam então substituir a distribuição de cestas básicas pela troca de produtos com ênfase em artigos produzidos pelos participantes. Havia, nessa proposta inicial, duas preocupações centrais: gerar algum tipo de renda e ressignificar o trabalho, demasiadamente atrelado ao mercado formal.

As trocas que poderiam ser diretas (produto por produto) ou mediadas por uma moeda social (cédula com validade apenas dentro dos clubes) incluíam basicamente comida e roupas usadas nesses primeiros anos. No entanto, a insistência na retomada de atividades como a produção de artesanato e o cultivo de hortas diversificou os itens trocados, sendo que 
atualmente trocam-se também mudas de plantas nativas, alimentos como pães e massas não industrializados, e demais itens considerados produção própria. Os grupos se multiplicaram obedecendo a especificidades locais, mas mantendo uma estrutura comum que confere certa identidade coletiva aos clubes de troca. A maneira de organizar os encontros pauta-se em uma espécie de roteiro: chegada dos participantes, acolhida e apresentação dos novatos, momento de mística/reflexão, momento formativo, trocas, lanche coletivo e avaliação do encontro.

Esse ordenamento, quase religioso dada sua regularidade, esconde aos olhares apressados 0 conjunto de dinâmicas sutis e complexas engendradas. No momento da apresentação, por exemplo, quando cada participante diz seu nome, com que trabalha, como chegou ao grupo, reúne relatos simples à primeira vista, mas que dão às novas participantes, majoritariamente mulheres, um recado claro: alguém está interessado na pessoa que eu sou, na minha trajetória. Da mesma forma os momentos de mística nos quais os temas de reflexão podem incluir questões sobre a conjuntura econômica, mas também os doentes da comunidade que precisam de ajuda, seja companhia para ir ao médico ou uma visita de cortesia.

É nas trocas, contudo, que o senso de coletividade se dá de forma mais explicita às observações. Independente de como se organiza o momento de trocar os produtos, há uma hierarquia das trocas em que as participantes de forma velada criam estratégias para favorecer uma ou outra colega que estejam atravessando maiores dificuldades econômicas. Se a ordem de trocar é determinada por sorteio os itens alimentícios vão sendo deixados de lado até que chegue a vez da participante que precise mais deles trocar. Esse "favorecimento" não é declarado, uma vez que enunciá-lo poderia expor a participante produzindo sobre ela a percepção subjetiva de depender da caridade das colegas. É exatamente aí que reside a importância das trocas: os sujeitos não são alvo da esmola, posição que hierarquiza inferiorizando quem a recebe, mas agentes que participam em condições mínimas de igualdade.

As trocas, todavia, não são materialmente desinteressadas. Há produtos mais cobiçados que outros. No entanto, o que regula o câmbio não é a paridade monetária, mas a necessidade. Se alguém precisa mais de determinado produto, o coletivo dará um jeito de que essa pessoa volte pra casa com o mínimo necessário para aquela semana. Os parâmetros de troca justa não passam por equivalências, são absolutamente contextualizados. Essa espécie de protecionismo funda-se em uma percepção de solidariedade fortemente informada pelo cuidado. As mulheres com crianças ou idosos em casa são alvo dessa atenção de maneira mais sistemática, exatamente porque as tarefas do campo do cuidado dificultam a realização de trabalhos remunerados ainda que precários, como os de diarista. As noções de justiça e solidariedade se estabelecem de maneira dinâmica e posicional tendo em consideração as condições específicas de cada participante. Não obstante cada grupo ser marcado por particularidades, existe um perfil médio: mulheres acima dos 40 anos, ensino fundamental incompleto, migrantes do interior do estado do Paraná, com experiência profissional como domésticas, zeladoras, diaristas, com filhos. Os arranjos familiares são diversos. Há participantes que ficaram viúvas e não desejam mais se casar, algumas permanecem casadas em função da dependência da renda do esposo, outras tentam equilibrar a rotina entre idas e vindas do marido:

Ele vai embora e volta direto, eu trabalho pra comer, não acabo minha casa, sempre foi meu sonho ter a minha casa. Ele chega e quer ser dono da casa, come e bebe o que eu compro. Pra eu me ver livre dele eu tinha que vender a casa. (Marli, 35 anos).

As relações intrafamiliares compõem em grande medida o que denominamos aqui "paisagem do medo". Há silenciamentos estruturais cristalizados no que os sujeitos compreendem que sejam papeis femininos e masculinos. Muitas delas estudaram apenas até onde o pai permitiu, mudaram-se para onde o marido achou conveniente, participam de atividades que não atrapalhem as obrigações que têm com os filhos. O que não significa se pensar que os papeis sociais impliquem em estagnação. Muitas delas lograram deslocar-se de determinadas posições de sujeito:

O meu, quando eu fiquei doente, que sentia muita dor, não tinha ninguém pra 
fazer... ah mas dançaram miudinho [o marido e o filho], minha filha vinha no final de semana lavar roupa, mas aí ela dizia: "eu não vou fazer nada, só vou lavar a roupa, quem quiser comer que coma". A minha filha é assim estourada, eu sei que eles começaram a fazer comida, começaram a botar feijão no fogo porque lá em casa ninguém come sem feijão [...] até bolinho pingado na gordura aprenderam a fazer, eles foram obrigado, pai e filho [...] sei que eu venci os dois lá de casa, agora até roupa eles lavam. (Célia, 55 anos).

A ideia de "eu venci os dois lá de casa" faz parte de um processo empreendido coletivamente pelas mulheres. Certamente que não se pode atribuir unicamente à participação no clube de trocas os méritos por essa mudança. No entanto, é fato que se produziu uma rede de proteção próxima que deu a essas mulheres alternativas, práticas, concretas ou mesmo no campo da subjetividade como aprofundaremos na seção seguinte.

\section{O silenciamento como contingência}

O pertencimento a territórios considerados violentos produziria sobre os moradores de tais regiões o que Luiz Antonio Machado da Silva (2008) classificou como sociabilidade dos confinados. Nessas condições de convivência, há uma linha tênue entre silenciar como maneira de se proteger e o silêncio visto como conivência. A necessidade de demarcação dessa fronteira se refaz a cada processo interativo: não se consomem drogas, não se confraterniza com os agentes do tráfico, entre outros. Porém, manter distância das práticas consideradas criminosas não é suficiente para não se participar de forma ativa dela. É preciso proteger-se da violência imprevisível, em casa e fora dela. No caso das mulheres entrevistadas, a principal ferramenta de proteção foi a fala. Saber falar foi relatado como uma das conquistas ou principal mudança no cotidiano desde o ingresso no clube. Os interditos sobre a fala dessas mulheres estão profundamente marcados pelas assimetrias de gênero, 0 que fica evidente nos relatos acerca do trabalho e das atividades domésticas:

Eu trabalhava como zeladora, faz um ano que eu parei, eu saí, fui obrigada a sair que não tinha mais condições, eu tinha que ficar no serviço, mas não podia trabalhar, porque desgastou a cartilagem, então não tinha condições de eu mexer mais na limpeza [...] fui no médico ele disse que eu tinha condição de voltar, eu voltei mas não aguentei [...] eu entrei em depressão sabe, pra mim nada prestava, eu não presto pra nada mesmo, alejada dos dois braços, perdi a força numa perna, o que que eu ia fazer. (Nilza).

Para a maioria delas, o fato de contribuírem apenas parcialmente para a renda da família as coloca na posição de tuteladas, de não sujeitos, ou ainda de sujeitadas. Não se pode questionar como o marido organiza o orçamento da família, é preciso pedir dinheiro para tudo o tempo todo. As tarefas domésticas, essenciais para vida, são essencializadas como femininas, enquanto obrigação exclusiva das mulheres, compondo parte da sua essência. Ocupar essa posição de sujeito dá à cidadania fronteiras territoriais, como a se a capacidade de acessar e usufruir seus direitos parasse na porta da casa. O desafio da reprodução material da vida é antecedido pelo problema do não reconhecimento de sua cidadania no espaço doméstico.

Em meio a esses contingenciamentos o crochê, a receita do bolo, a planta trazida da horta para a troca ganharam status de trabalho reconhecido como tal pelo coletivo, a partir do momento que alguém se interessou por esses produtos. O que era "coisa de mulher" ganha um novo conteúdo: trabalho socialmente útil. É preciso ao chegar ao clube, apresentar-se e apresentar o que trouxe para trocar, dizer o que fez com as próprias mãos e dizer quanto vale aquele trabalho. É falar sobre valor, não preço. Falar em público, no clube de trocas, é uma conquista e um aprendizado, capaz de informar novos padrões de conduta, que se irradiam também para espaço doméstico.

$\mathrm{O}$ que, em um primeiro momento parece refletir elementos intersubjetivos em escala microssocial, conecta-se com reflexões propostas por Richard Sennett (2005) na obra A Corrosão do Caráter. Segundo o autor, uma das principais características do capitalismo flexível é que ele retira dos indivíduos a possibilidade de desenvolver uma narrativa de 
identidade. Em sua nova forma, o capitalismo possibilita apenas fragmentos episódicos, as reengenharias do tempo, que agora transformado em produto, mercadoria, demoniza qualquer forma de rotina sem considerar que "imaginar uma vida de impulsos momentâneos, de ação em curto prazo, despida de rotinas sustentáveis, uma vida sem hábitos, é na verdade imaginar uma existência irracional" (SENNETT, 2005, p. 50). A vida em fragmentos deixa pouco ou nenhum espaço para construção de laços de reciprocidade ou mesmo de confiança, necessários ao estabelecimento de redes e coesões mínimas. Adentrar as discussões sobre violência, por exemplo, implica em um universo repleto de acordos tácitos desconhecidos para indivíduos alheios ao cotidiano da comunidade. Há falas não autorizadas, mais que isso, a fala, o falar, e, sobretudo, o falar corretamente, mostrou-se senão o único instrumento de poder, o mais acessível.

Em diversos momentos, procuramos apreender as representações individuais e coletivas a respeito do bairro onde acontecem os encontros. De acordo com notícias veiculadas em meio digital, o município onde moram vem sendo tomado por uma onda de violência ${ }^{4}$. No entanto, a fim de não direcionarmos ou mesmo induzirmos as respostas, a pergunta inicial era "como é viver aqui?". Os primeiros relatos davam conta de afirmar que é um bom lugar para se viver, sempre associados a comparações com a vida no interior do estado e o trabalho na lavoura. Apenas uma entrevistada falou no primeiro contato mais diretamente sobre violência: "a vida inteira eu morei aqui, criei meus filhos aqui, eu gosto, o que acontece é que é violento" (Dalva). A partir desse relato procuramos nos aprofundar no sentido do que a entrevistada estava chamando de violento, violência:

Tem muita droga, por isso que eu acho que tem a violência, principalmente por causa da droga, se não fosse isso não tinha [...] e com a droga vem outras coisas, com nós [no grupo] tem uma que perdeu o filho por isso, ele usava droga, pra começar a usar eles dão, depois. (Dalva).

Mais adiante, perguntamos sobre a presença da polícia na comunidade:

É uma coisa que eu vou dizer pra você, eu não sei como, o que as policia faz que não fazem nada [há uma perceptível mudança no tom de voz agora quase sussurrado] a gente já viu pega gente que vende as coisa, sabe que vende, mas vai lá [com a policia] e já volta, tá na rua, alguma coisa tem de errado. (Dalva).

Essa mudança no tom de voz ao falar sobre a atuação da polícia nos remete novamente ao falar e, nesse caso, ao não falar como um padrão de sociabilidade violenta, como conceituou Luiz Antonio Machado da Silva (2008). De acordo com Silva, esta sociabilidade caracteriza-se pela imposição mediante o uso da força da vontade de uns sobre outros. Não há entre os atores compartilhamento de valores que pudessem em algum nível regular o uso da força física.

A ausência desses valores ou de qualquer outra espécie de regulamentação retira a possibilidade de previsibilidade das ações, retirando dos atores a possibilidade de estabelecer uma rotina. Todas as atividades cotidianas e assuntos dos moradores comuns são influenciados pela sociabilidade violenta. Em uma das comunidades visitadas, por exemplo, reuniões à noite só poderiam acontecer na Igreja e para estudar bíblia. Na sociabilidade violenta, o uso da força física aplicada ilicitamente é transformado de meio para obtenção de interesses em princípio norteador das ações. Não é mais possível acessar instâncias políticas ou morais. Os agentes desse ordenamento não se pautam por referências coletivas, mas pela satisfação imediata de seus interesses, sendo que a única resistência oferecida é a força de outrem. Silva afirma ainda que referências como amizade, afeto, relações familiares, foram substituídas por uma cadeia de submissão organizada hierarquicamente pela força.

Para os moradores sujeitos à sociabilidade violenta há uma dupla dominação: de fora da comunidade são vistos como violentos, visão que associa pobreza e crime, e internamente são forçados a conviver com o padrão de sociabilidade violenta imposto pelos criminosos. De um

\footnotetext{
${ }^{4}$ Notícia disponível em: <http://bandab.pron.com.br/jornalismo/em-onda-de-violencia-inedita-almirantetamandare-registra-16o-homicidio-em-apenas-27-dias-18514/> Acesso em: 23 nov 2011.
} 
lado, temos então um senso comum alimentado midiaticamente que associa pobreza e violência e os moradores de periferias ao crime, estabelecendo uma segregação violenta, mais que isso, produzindo uma crescente deslegitimação de suas demandas. A proximidade física entre moradores e criminosos é, com frequência, interpretada como uma proximidade também moral, ou seja, o que para os moradores é uma situação de confinamento compulsório, a outros olhares é conivência.

A recorrente aproximação entre pobreza e violência é tributária de antigos fantasmas. Se antes eram temidas revoltas populares capazes de abalar a dominação burguesa, agora a violência associada aos territórios pauperizados e aos pobres, orienta políticas públicas de segurança cada vez mais segregacionistas. O que se interpreta como conivência, o silêncio ou diferentes formas de omissão não podem ser tomados como evidência de passividade ou de adesão ao crime e seus agentes. Constitui, antes de tudo, uma estratégia de sobrevivência e convivência, uma tentativa de defesa frente às ameaças à segurança pessoal, como para uma de nossas entrevistadas: "a gente sabe quando dá pra falar, quando não dá". Os relatos sobre violência no caso do bairro só começaram a surgir após quase três anos de convivência e, ainda assim, quando estimulados.

De acordo com Silva (2008), os estigmas sociais sofridos pelos moradores dificultam e muitas vezes inviabilizam o acesso a soluções institucionais para os riscos que sofrem. Além disso, o medo e a desconfiança alimentados também por esses estigmas enfraquecem os laços sociais e comunitários, mesmo as relações de vizinhança capazes de restabelecer minimamente uma proteção próxima. A outra face da segregação sofrida pelos moradores se dá pelo convívio forçado, especialmente com traficantes, que impõem sobre esses moradores um padrão de comportamento baseado na insegurança e imprevisibilidade, "um 'mal-entendido' quase sempre resulta na morte de alguém" (Silva, 2008, p. 43).

Nesse sentido, o autor desenvolve a noção de sociabilidade dos confinados, obtida a partir de estudos em comunidades cariocas nas quais o convívio forçado entre moradores e agentes da criminalidade produz uma sociabilidade regida majoritariamente pela "lei do silêncio". Nas palavras do autor, "o confinamento geográfico cerceia-Ihes também a palavra" (SILVA, 2008, p. 15). O esforço em promover uma "limpeza moral" é constante. Os moradores procuram continuamente demarcar moralmente sua distância em relação aos traficantes e ao crime, uma vez que a demarcação espacial e geográfica não é possível:

Dentro das favelas, os moradores também procuram deixar claro seu distanciamento moral em relação aos traficantes. Não fumar maconha, não cheirar cocaína, não se envolver em seus negócios e redes e não aceitar seus favores são formas de tornar clara para os vizinhos a condição de 'pessoa de bem' e a adesão a ordem institucional. (SILVA, 2008, p. 23).

No relato de uma das participantes do clube, fica clara a angústia gerada pela possibilidade de associação dos familiares, especialmente filhos, ao crime: "eu tenho uma irmã que disse - pelo amor de Deus, deixa ele trabalhar lá, eu dou o dinheiro pra pagar o salário dele. Ela chegava e o menino na rua, era só pra ele fica ocupado, não tem onde deixar..." (Dalva). O filho da entrevistada possui um pequeno comércio no qual emprega alguns familiares, a irmã da entrevistada faz um apelo desesperado pra manter o filho adolescente "a salvo" dos perigos do tempo ocioso. Percebemos uma espécie de "rede de mães" que se mobilizam para "salvar" os filhos. Mesmo que a adesão ao crime não seja um destino inevitável, os jovens são percebidos em permanente risco de envolvimento. Nos estudos de comunidades no Rio Janeiro, a atuação das mulheres, especialmente mães, se destacou como um "estatuto moral" capaz de impor respeito aos traficantes (SILVA, 2008, p. 23). Para nossas entrevistas, uma das alternativas foi organizar uma escala para buscar os filhos que voltam à noite do colégio.

Poderíamos dizer, portanto, que a sociabilidade nas comunidades periféricas possui duas faces: a sociabilidade violenta acionada por alguns atores com o auxílio de artefatos como armas, por exemplo, e a sociabilidade dos confinados acionada pelos membros da comunidade que precisam adaptar seu cotidiano de modo a evitar não apenas as manifestações da 
sociabilidade violenta, mas também evitar uma espécie de contágio moral. A ideia do silêncio como estratégia de convivência, e mesmo de sobrevivência, está bastante presente no cotidiano das mulheres entrevistadas. Há alguns anos, ganharam visibilidade diversos casos de execução de mulheres na região onde acontecem os encontros e onde moram as entrevistadas. Segundo a jornalista Alana Rizzo ${ }^{5}$, foram 35 mortes de mulheres em condições semelhantes no período de 1994 a 2002, todas jovens com sinais de tortura e violência sexual, sendo que os corpos eram "desovados" em matagais a fim de dificultar os procedimentos para reconhecimento das vítimas, uma vez que a maioria foi encontrada em adiantado estado de decomposição. Outras fontes da época ${ }^{6}$, dão notícias de 21 casos e, destes, apenas um teve as investigações concluídas.

Especulações da época davam conta de que as vítimas estavam de alguma forma ligadas ao tráfico de drogas e prostituição, como que em um esforço de aproximar das vítimas com a criminalidade e tornar suas mortes menos impactantes ou mesmo legitimadas, como ilustra a fala da delegada responsável pelas investigações:

Elas, na maioria eram viciadas em drogas e tinham que vender o produto para sustentar o vício [...] quando já estavam sabendo demais sobre as atividades da quadrilha, eram sequestradas, mantidas como reféns, assassinadas e seus corpos 'desovados' no mato somente quando já estavam em decomposição?

Durante a realização de um dos grupos focais e a partir do relato das participantes de que o bairro era violento, foram perguntadas especificamente sobre esse caso das mulheres mortas, o que sabiam, como estava a situação naquele momento:

A televisão falou que era prostituta, que vendia droga, mas não era, era trabalhadora, teve até a [cita nominalmente uma das vítimas conhecida por elas]. (Silvia).

Começaram a descobrir tem pouco tempo, ainda morre alguma, só que começaram a descobrir depois, ninguém sabe do que [do porque as mulheres eram mortas] eles pegavam, estupravam e matavam, eles ia achando a roupa conforme ela ia correndo, achava a calcinha perto do corpo. No fundo, no fundo a gente não sabe o que que é, sabe que é bandido mesmo. (Dalva).

Algumas delas participaram de uma das inúmeras manifestações pela apuração das mortes, quando perguntadas se não tiveram medo uma delas respondeu: "se a gente ficar quéta eles não vão parar [...] tem hora que dá pra falar, tem hora que não" (Silvia). Destacamos o relato por considerar que reflete de maneira clara o que representa o saber falar como um padrão de sociabilidade aprendido e apreendido. Não é suficiente saber o que e como dizer, mas quando e em que contexto.

\section{O SILÊNCIO COMO ESTRATÉGIA}

\footnotetext{
${ }^{5}$ Disponível em:

<http://www.feminismo.org.br/livre/index.php?option=com_content\&view=article\&id=4136:a-qfirmaq-queassassinava-mulheres-em-almirante-tamandare-no-parana\&catid=126:violencia-\&ltemid=533>Acesso em: 23 nov.2015.

${ }^{6}$ Disponível em: <http://www.parana-

online.com.br/editoria/policia/news/22324/?noticia=TESTEMUNHAS+FALAM+DOS+CRIMES+EM+TAMA NDARE> Acesso em: 23 nov 2015.

${ }^{7}$ Disponivel em:

<file:///C:/Users/Maria\%20lzabel/Documents/Temp/Testemunhas\%20falam\%20dos\%20crimes\%20em\%20

Tamandar\%C3\%A9\%20-\%20Paran\%C3\%A1-Online\%20-

\%20Paranaense\%20como\%20voc\%C3\%AA.htm> Acesso em: 23 nov 2015.
} 
Desde os primeiros relatos e mesmo em outros grupos que tivemos oportunidade de conhecer, o clube de trocas mostrou-se um divisor de águas atuando primordialmente como um espaço onde as pessoas podem falar e ser ouvidas:

Aqui a gente partilha tudo, até tristeza. (Seu José)

Eu gostei de vir que aqui a gente pode desabafar. (Cleonice, Clube de Troca Novo Amanhecer)

Eu tinha medo de falar, de falar errado, de falar alto, eu comecei e me isolar. (Silvia)

Que nem eu parei de trabalhar, fiquei em casa sem poder conversar com as pessoas, sei lá, conversar, explicar porque você tá sentindo, comigo não tinha isso, cada dia que passava o problema de saúde ia aumentando mais, porque daí você vai acumulando problema no seu corpo [...]. (Célia)

A Joana disse 'eu vou te levar [no encontro do Clube de Trocas]', aí eu disse 'eu vou, eu vou conhecer, mas cê sabe quando cê tá com depressão, tá pra baixo, não tem o que faz a gente mudar [...], daí cheguei no Troca e fiquei com medo deles não me aceitarem, porque quando a gente tava chegando lá a Joana falou: Silvia, pode ser que hoje você não participa, você é uma visita só e se eles te aceitarem a partir de hoje você já faz parte do grupo, senão te aceitarem, daí não sei quando, só quando tiver uma vaga, não fica chateada [nesse grupo o número de participantes era limitado em função da distribuição de cestas básicas]. Eu falei 'não, não', mas eu pensava como que ela me chama e daí aqui que ela vai me avisar, depois chega lá eles não vão me aceitar eu vou voltar chateada, daí acho que eu não devia ter nem vindo. Daí lá tinha bastante gente, na hora que ela falou, comentou [consultando sobre o ingresso no grupo], eles tem uma coisa que eles são muito unido, quando um tava falando todo mundo ficava ouvindo, prestando atenção, daí a Adriana [assessora do grupo], quem resolve é vocês, o grupo é de vocês, se quiserem que ela entra pro grupo vocês resolvem [...] no primeiro dia eu não tinha levado nada pra trocar [...] aí resolveram, cada um deu uma opinião, sei que daí eu fui acolhida no grupo no mesmo dia, eu já trouxe o mantimento, daí pra cá comecei, quando eu comecei eu tava passando por muita dificuldade, e as vezes tava sem nada, eu vivia do salarinho do bolsa família. [...] no primeiro dia eu chorei muito, nem consegui falar, no segundo dia eu disse: eu tenho que falar, eu tava com vontade de falar, eu tinha que agradecer, mas tinha uma coisa que me segurava. (Silvia)

O falar a partir dos relatos está diretamente relacionado ao saber e o saber valorizado socialmente é o escolar. Há um trabalho intenso por parte dos assessores que acompanham o grupo no resgate do saber popular como um saber válido. Em um momento de mística lia-se em um cartaz: "todos têm um saber que deve ser valorizado. $O$ mundo não pode se dividir entre os que sabem e o que não sabem". A frase expressa o movimento realizado pelos participantes ao longo dos encontros de resgate e valorização das trajetórias e saberes individuais. Em um dos momentos de entrevista em grupo, a temática do falar apareceu de forma mais articulada e explícita. Sete das mulheres com quem foi possível um contato mais profundo vieram do interior do estado, de comunidades rurais. Há um contraste estabelecido a partir de situações cotidianas que delimitam os contornos do urbano e do rural, de forma 
hierárquica, inclusive. Os padrões de conduta, o vocabulário, o sotaque da "cidade" são tomados como a maneira correta de falar.

A saída do campo com destino à capital já se dá acumulando desvantagens objetivas e subjetivas. Todas relataram que trabalhavam na lavoura em pequenas propriedades familiares. Uma declarou ter trabalhado também como boia-fria. Com acesso bastante restrito à educação formal. Partindo disso, ao chegarem em busca de colocação profissional encontraram o mercado de trabalho bastante seletivo e restritivo, exigindo cada vez mais qualificações e especializações técnicas. As colocações possíveis restringiram-se à área de limpeza e conservação, como empregadas domésticas, sem vínculo empregatício ou como zeladoras de condomínios, o que possibilitou a uma delas a aposentadoria por invalidez, duramente recebida pela beneficiária: "eles queriam me aposentar por invalidez e eu não queria aceitar isso [...] daí eu decidi 'vou deixar eles me aposentarem, mas não vou ficar inválida”'.

A compreensão desse processo, especialmente a impossibilidade de adequar-se às exigências do mercado de trabalho, dão-nos a dimensão do falar na trajetória de cada uma delas. Deixar para trás os vínculos familiares e partir para a cidade grande contando apenas com uma escolarização precária, somada às limitações para o desenvolvimento de uma identidade profissional garantidora de proteções, colocou essas mulheres em uma situação de vulnerabilidade, uma vez que as proteções próximas da família e comunidade, como denominou Castel, já não estavam presentes. Mesmo com todas as dificuldades, a vinda para as imediações de Curitiba representou uma melhora significativa nas condições de vida:

Eu arrependo de não ter vindo antes. A vida inteira aqui eu trabalhei de diarista, acho muito melhor trabalhar de diarista aqui do que trabalhar na roça igual nós trabalhava lá, porque eu acho que cansa menos e porque paga melhor. (Dalva).

O clube de trocas se estabeleceu como um espaço de acolhida que permitiu a ressignificação e consequente revalorização do próprio saber: "o pessoal diz: ele não fala o português correto, eu acho que o português correto é o que você entende." (Silvia). O que não significa, contudo, que a sociabilidade aprendida durante a vida no campo tenha sido esquecida ou mesmo que 0 modo urbano de falar ou se comportar tenha sido completamente apreendido:

\footnotetext{
Eu fui pro norte do Paraná, eu me senti bem, todo mundo fala do jeito que eu falo [...] hoje aqui na cidade é tudo diferente, pequeneninho já querem ensinar a criança a falar diferente, falar direito, falar não sei como, e eu não sei até que ponto as coisas de hoje é bom pras pessoas, porque eu acho que o mais certo era deixar espontâneo. (Silvia).
}

Ao tratar, portanto, de novas sociabilidades em construção, não podemos ignorar o falar como um novo padrão de sociabilidade central e determinante principalmente para as mulheres que participam dos grupos. O falar dentro do grupo parece receber outro caráter em relação a espaços como a família e nas relações de convivência com a vizinhança. A fala no clube de trocas vem sempre acompanhada da escuta atenta: 


\begin{abstract}
Aqui a gente faz o que a gente quer, a gente tem vez e voz, no grupo não tem ninguém melhor do que ninguém, se você chegar no grupo você é bem acolhido, você pode falar o que você quiser, você pode desabafar, ninguém te repreende, se você tá com problema você chega lá, você fala, se você tem uma coisa que não gostou no grupo você pode falar, a gente não briga, a gente procura resolver junto. (Silvia, grifamos).
\end{abstract}

Que nem, quando eu parei de trabalhar fiquei em casa sem poder conversar com as pessoas [...] e no grupo não, a gente conversa, se um não concorda a gente conversa com todo mundo por que não concorda, a gente brinca, conversa de novo, mostra onde tá o erro, e assim a gente vai se libertando, vivendo, é uma vivência. (Celia).

Essa possibilidade de falar e ser ouvido está diretamente relacionada à superação do isolamento. As culturas conhecidas como tradicionais, às quais se alinhavam valores como a cooperação e solidariedade, perderam espaço para o que Castel (2009) chamou de individualismo negativo. A emergência da noção de indivíduo como um ser autônomo, moral e, sobretudo, independente remete à noção de liberdade, de certa forma esse indivíduo moderno não estaria mais sob os auspícios dos enquadramentos coletivos que o privavam das expressões de suas particularidades. Para Moraes, seria uma "forma de existência mais ou menos descolada do coletivo ou da comunidade" (MORAES, 2006, p. 70), que o desobrigava das submissões medievais.

O que para Robert Castel tornou-se um problema é que a figura de um indivíduo empreendedor de si mesmo, "senhor de seus empreendimentos" (CASTEL, 2009, p. 596) encobriu uma das faces perversas da modernidade em que se combinam a total independência dos indivíduos com sua completa ausência de consistência. Se por um lado este indivíduo está, em alguma medida, livre dos encastramentos coletivos, por outro, ao pertencer unicamente a si mesmo, está superexposto. Desprende-se do tecido social e deixa de contar com redes de proteção próximas. A imagem utilizada por Castel para definir esse individuo é de um ser flutuante no tecido social, sem amarras, mas também sem alguém a quem recorrer.

Trata-se de individualismo competitivo, diferente do alinhado à ideia de respeito à liberdade individual. O outro, neste modelo competitivo de sociedade, é a ameaça à vaga de trabalho, à cadeira na universidade, etc. A competição sem freios ou regulamentação se coloca como a única maneira de ocupar posições uma vez que elas não existem para todos. Além disso, o autor chama a atenção para o fato de que há contradições no atual processo de individualização. Há uma polarização, um abismo: de um lado os que podem associar individualismo e independência por terem garantidas prerrogativas econômicas e sociais básicas, de outro estão os que percebem esse individualismo como como um fardo, mesmo uma cruz porque significa falta de vínculos e ausência de proteções (CASTEL, 2009, p. 610). O cenário torna-se ainda mais preocupante na medida em que se constata que é uma ilusão supor que a elevação no nível de escolaridade, embora legítima e necessária, seria capaz de garantir de alguma forma colocação no mercado formal de trabalho. Estamos diante de um novo problema: a possível não empregabilidade dos qualificados. (CASTEL, 2009, p. 521). A questão chave para o autor quanto à precarização do emprego e o aumento do desemprego é que ambas representam a manifestação de um deficit de lugares ocupáveis na estrutura social. Posições essas associadas a uma utilidade social e reconhecimento público: 
O salário reconhece e remunera o trabalho 'em geral', isto é, atividades potencialmente úteis para todos. Assim, na sociedade contemporânea, e para a maioria de seus membros, é o fundamento de sua cidadania econômica. Também está no princípio da cidadania social: esse trabalho representa a participação de cada um numa produção para a sociedade e, portanto, na produção da sociedade. É assim o ponto médio concreto sobre o qual se constroem direitos e deveres sociais, responsabilidades e reconhecimento, ao mesmo tempo sujeições e coerções. (CASTEL, 2009, p. 581).

O déficit de lugares está na raiz da desvinculação, ou mesmo da invalidação social sofrida pelos desfiliados. Robert Castel não utiliza a expressão exclusão ou excluídos por considerar que estas mascaram um processo dinâmico, construído socialmente de invalidação social. Para este contingente, a identidade pelo trabalho está perdida. Os "inúteis para o mundo" teriam poucas escolhas: a resignação e a violência esporádica, ambas autodestrutivas. A participação em um grupo exerceu o papel que o mercado formal de trabalho deixou de fazer. Como explica Célia, depois que precisou ser afastada do trabalho por problemas de saúde: "eu entrei em depressão... eu dizia 'a gente não presta pra nada mesmo'". Após os primeiros encontros foram, de acordo com os relatos, se sentindo mais valorizadas, as produções que levavam as fizeram perceber que tinham conhecimentos e experiências que poderiam ser trocados e que ajudariam muitas outras pessoas:

E faz bem pra gente vim aqui, a gente não entra em depressão. Eu trabalhava como zeladora, faz um ano que eu parei, eu saí, fui obrigada a sair, não tinha mais condição. Eu tinha que ficar no serviço, mas não podia trabalhar porque desgastou a cartilagem então não tinha mais condição de mexer com limpeza, o médico disse que eu tinha condição, mas eu voltei e não aguentei [...] aí eu achei melhor lutar, aí falei: vou lutar pela minha vida! (Célia).

Nesse sentido, a participação no grupo passou a constituir a identidade de seus participantes na medida em que se identificaram com os demais e se sentiram, de alguma maneira, "úteis", ao poderem ensinar o que sabem e aprender coisas novas, mesmo com a pouca escolaridade que têm. No caso das mulheres do clube, dizer sua palavra e encontrar audiência atenta e acolhedora criou no grupo um sentido profundo de pertença: "se acontece alguma coisa com uma dessas muié (sic), todo mundo já sabe no outro dia" (Dalva). Para Sennett, quanto maior o senso de comunidade dos 'fracassados' do capitalismo, maior a capacidade de reorganizar as narrativas de vida de forma sustentável. Para ele, um lugar torna-se uma comunidade quando começamos pensar a partir de um 'nós'. As condições impostas pelo capitalismo flexível como as incertezas da flexibilidade, a ausência de confiança e o "espectro de não fazermos nada de nós mesmos no mundo" (SENNETT, 2005, p. 165) levam as pessoas a buscarem ligações capazes de romper com esse ciclo:

\begin{abstract}
A gente vai na casa das pessoas pra incentivar elas ir no grupo e tamo fortalecendo api, a gente dá conselhos pras mulheres que ficaram na mesma situação que a gente, pensando né que o mundo acabou, que se a gente não tiver um emprego a gente não vive, é pra elas vim pro grupo conhecer que a gente pode viver com outros tipos de trabalho, não é só de empregado que a gente vive, é como fala na Economia Solidária a gente vive um outro tipo de vida, uma outra experiência, uma outra história, que a gente não conhece a gente pensa que não vai dar certo. (Silvia).
\end{abstract}

Nos primeiros contatos foi possível constatar um movimento para fora do grupo através da participação em outras atividades e cursos. Um deles, oferecido à comunidade, mas especificamente às participantes do clube de trocas, era sobre violência contra mulher e a Lei 
Maria da Penha:

\begin{abstract}
As mulheres aqui a gente fez um mês de curso sobre a Maria da Penha, depois do curso teve uma mulher que denunciou, já deu resultado, não deu cem por cento, mas já deu. Uma mulher vai falando com a outra, ninguém se prevalece mais, é um jeito de uma cuidar da outra, não vai enfrentar homem, é tudo pela lei, ninguém o obrigado a viver com ninguém... a menina fez 0 curso e o marido se emendou. (Dalva).
\end{abstract}

A possibilidade de organizar narrativas, tanto para os sujeitos da obra de Sennett quanto para as participantes do clube, demonstrou ser o ponto de apoio, a alavanca através da qual é possível ultrapassar a noção de fracasso pessoal e ressignificar a própria trajetória, seus valores e práticas.

\title{
CONSIDERAÇÕES FINAIS
}

Ultrapassando o momento e o valor material das trocas propriamente ditas, a participação no grupo representou a possibilidade de criar vínculos e laços de confiança que o mercado de trabalho deixou de possibilitar. Além disso, o clube se constituiu como um mediador capaz de ouvir a indignação e a revolta moral e convertê-la em demanda política, acionando a linguagem dos direitos. Dois movimentos para fora do grupo merecem destaque: a participação na manifestação contra os assassinatos das mulheres na região e a participação no curso sobre a Lei Maria da Penha. Nenhuma dessas ações seria possível se antes essas mulheres não tivessem aprendido a dizer a sua palavra. Para que isso fosse possível foi necessário constituir internamente um coletivo de confiança, onde cada uma pudesse colocar suas angústias não pronunciadas ou não ouvidas em outros espaços: "eu tô saindo daqui aliviada, parece que saiu um peso", relata uma das participantes durante a avaliação de como foi um dos encontros.

Ao tratarmos, portanto, de um novo padrão de sociabilidade experimentado a partir do grupo, referimo-nos ao deslocamento de uma percepção de si orientada por perdas concretas e simbólicas acumuladas por essas mulheres. A migração do interior do estado e 0 enfrentamento das regras implacáveis de concorrência no mercado de trabalho se somam às dificuldades vividas no ambiente doméstico. O "não saber falar" acompanhado do medo de "não ser aceita" pelo grupo estavam, na maioria das vezes, informados por um padrão de relações no espaço doméstico em que a cidadania ficou fora de casa. Por isso não cabe questionar se essas mulheres não falavam antes, falavam, mas na condição de não-pessoas.

Quando se introduz o elemento reciprocidade como base para as relações "falar" vem acompanhado de "ser ouvida", o que representa nesse contexto o reconhecimento desse indivíduo como pessoa, alguém digno de ser ouvido por um coletivo, alguém que tem algo importante a dizer. As questões sobre saber falar implicam também em saber a hora certa de falar. O que explica, por exemplo, que as atividades do grupo, ou mesmo as mulheres individualmente, nunca tenham sofrido algum tipo de represália por parte de criminosos que controlam a região. É preciso adaptar-se à lógica imposta pela violência sem que essa adaptação represente apoio ou conivência. Os contingenciamentos impostos pelas transformações no mundo do trabalho e o contexto periférico no qual vivem as entrevistadas sobrepôs padrões de sociabilidade baseados no confinamento, como desenvolvido por Silva e o individualismo negativo como discutido por Castel. Dentre os desafios enfrentados pelas participantes dos clubes estão a superação da pobreza, condição estrutural e seus efeitos intersubjetivos. O modo como a produção de "inúteis para o mundo", segundo as regras do capitalismo flexível, impacta a percepção de si das mulheres relaciona-se de maneira muito próxima a um conjunto de outras assimetrias sociais silenciadoras e segregadoras.

O estabelecimento de um coletivo de confiança possibilitou, no entanto, que mesmo diante 
desse confinamento da palavra e das ações, o grupo se mobilizasse contra o assassinato de mulheres na região. É um novo padrão de sociabilidade em construção que ultrapassa as ressignificações individuais, irradiando-se para a participação cívica e o reconhecimento do outro como um ser de direitos, ou como chamamos aqui, uma Rede de Proteção.

\section{REFERÊNCIAS}

CASTEL, Robert. As metamorfoses da questão social: uma crônica do salário. Petrópolis: Vozes, 2009.

IPARDES 2016 - Caderno Estatístico Município de Almirante Tamandaré - disponível em http://www.ipardes.gov.br/cadernos/MontaCadPdf1.php?Municipio=83500 - acesso em 20 abr 2017.

MACHADO, Maria Izabel. "Aí a gente vai sendo solidária e as pessoas vai revivendo": o Clube de Troca e a construção da sociabilidade. 2012. Dissertação (Mestrado em Sociologia). Universidade Federal do Paraná - UFPR, Curitiba, 2012. Disponível em: $<$ http://www.humanas.ufpr.br/portal/pgsocio/files/2012/12/R-D-MACHADO-MARIA-

IZABEL.pdf>. Acesso em: 09 mai 2016.

Mulheres, economia solidária e a reinvenção de trajetórias. Tese (Doutorado em Sociologia). Universidade Federal do Paraná - UFPR, Curitiba, 2017. Disponível em: http://acervodigital.ufpr.br/bitstream/handle/1884/46349/R\%20-\%20T\%20-

\%20MARIA\%20IZABEL\%20MACHADO.pdf?sequence=1. Acesso em: 06jan 2018.

MORAES, Pedro R. B. Émile Durkheim. Para uma sociologia do mundo contemporâneo. In: CODATO, Adriano (org.). Tecendo o Presente - Oito autores para pensar o século XX. Curitiba: Sesc Paraná, 2006. p. 67-85.

SENNETT, Richard. A Corrosão do Caráter - Consequências pessoais do trabalho no novo capitalismo. Rio de Janeiro: Record, 2005.

SILVA. Luis Antonio Machado da. Vida Sob Cerco. Rio de Janeiro: Nova Fronteira, 2008.

Recebido em: 09/10/2018

Aceito para publicação em: 24/03/2019 